Gynäk. Rdsch. 1974;14(Suppl. 1):111-112

\title{
Beeinflussung der Spermienmotilität
}

J.A.

Balmer

Universitätsfrauenklinik (Direktor: Prof. M. Berger), Bern

Adresse des Autors: Dr. J. A. Balmer, Universitätsfrauenklinik, Schanzeneckstrasse 1, CH-3012 Bern (Schweiz)

Nach einer 10 Tage dauernden sexuellen Karenz wurde bei 11 verheirate-ten Vätern eine optimale durchschnittliche Spermatozoenzahl von 176 Mio ermittelt. Aufgrund dieser Ergebnisse wurden andrologische Untersuchun-gen an einer infertilen Gruppe nach einer Karenz von 10 Tagen vorgenom-

MiII./mt

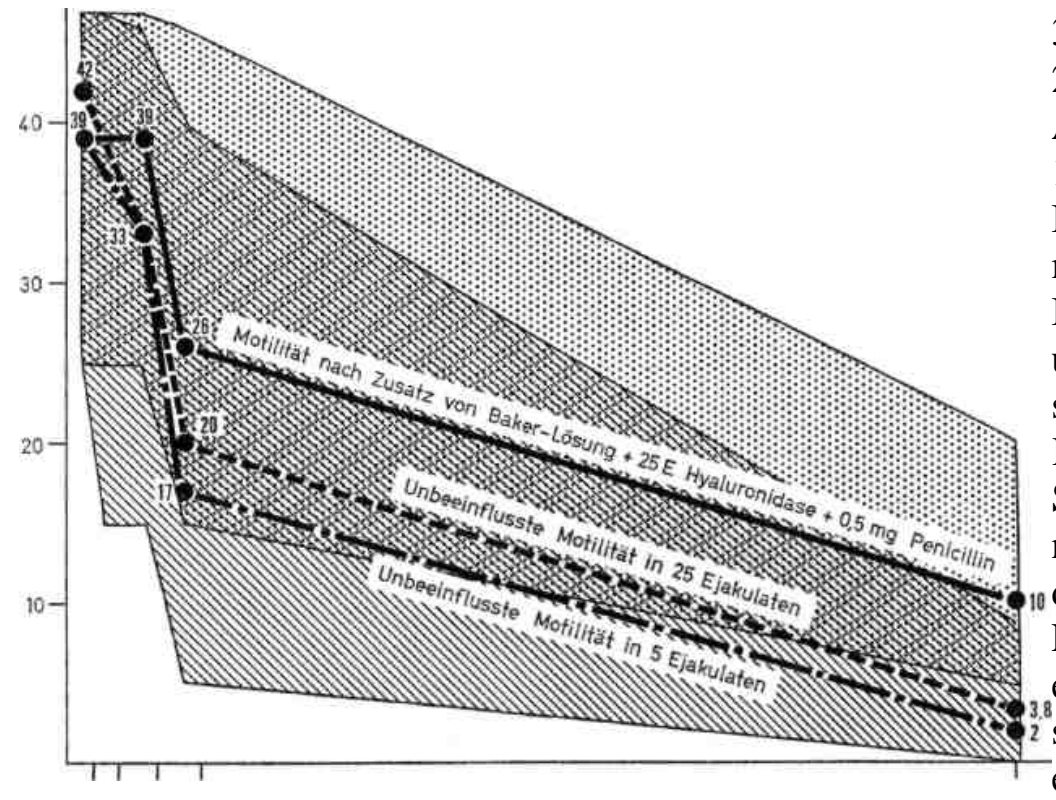

$3060120180 \mathrm{~min}$

$24 \mathrm{~h}$

Abb. 1. Spermienmotilitätsabfall.

112

Balmer

men. Die Versuchsreihe zur

Beeinflussung der Spermienmotilität umfasste 5 Probanden mit im Mittel seit 5,2 Jahren bestehendem

Kinderwunsch. Die durchschnittliche Spermatozoenzahl in Mio/ml zählte nach 10 Tagen Karenz 148,8. Die durchschnittliche Motilität in alien Ejakulaten ohne Beeinflussung nach einer Karenz von 10 Tagen zeigte sich mit rund 40,6\% 30 min post ejacu-lationem unter der Norm (Abb.

1

mittlere Kurve) und verminderte sich auf 38,2

33,4

20,2 bis 3,6\% entsprechend 1

2

3 und 24 h post ejaculatíonem. Die durchschnittlichen Motilitätswerte aller 5 Probanden ohne Beeinflussung ermittelten sich im 5. Beeinflussungsversuch wie folgt: (Abb. 1

untere Kurve): 39

37

33

17 und 2\%. In diesem Versuch zur Beeinflussung der Spermienmotilität wurde ein Teil Ejakulat mit einem Teil Bakerscher Lösung unter Zusatz von 25 E Hyaluronidase (Hyason Organon) und 0,5 mg Penicillin vermischt. Die initiale Motilität (Abb. 1 
obere Kurve) von 39\% (30 min p. ejac.) blieb bis 2 h nach Ejakulation konstant sank in der 3. Stun-de auf 26 und in der 24. Stunde auf 10\%. Wenn auch diese Resultate einen möglichen und weiterzuverfolgenden Weg zur positiven Beeinflussung der Spermienmotilität innerhalb der physiologisch relevanten Zeiteinheit auf-zeigen mögen

müssen dennoch geringe Abweichungen der Bewegungsinten-sität und Bewegungsdauer der Spermien mit äusserster Vorsicht beurteilt werden. 